\title{
Intraindividual Variability in Adolescents' Perceived Relationship Satisfaction: The Role of Daily Conflict
}

\author{
Muriel D. Van Doorn · Susan J. T. Branje • \\ Joop J. Hox · Wim H. J. Meeus
}

Received: 24 April 2008/Accepted: 25 June 2008/Published online: 8 July 2008

(C) The Author(s) 2008

\begin{abstract}
A daily diary method was used to examine the daily dynamics of adolescent conflict and perceived relationship satisfaction with mothers, fathers, and best friends among a sample of 72 Dutch adolescents $(M=15.59$ years). Multilevel analyses revealed that perceived relationship satisfaction with mothers, fathers, and best friends was lower on days on which conflict occurred with mothers, fathers, and best friends than on days on which no conflict occurred. More specifically, perceived relationship satisfaction was highest in a particular relationship on days when no conflict occurred, second highest on days on which constructive conflict occurred, and lowest on days on which unconstructive conflict occurred. Whereas in adolescents' relationships with their parents, conflict and perceived relationship satisfaction were not found to be related to each other one day later, conflict with their best friends-and especially unconstructive conflict-was found to be related to higher perceived relationship satisfaction one day later.
\end{abstract}

Keywords Parent-adolescent relationships . Friendships · Conflict · Conflict resolution · Diary

M. D. Van Doorn $(\bowtie) \cdot$ S. J. T. Branje · W. H. J. Meeus Research Centre Adolescent Development, Utrecht University, P.O. Box 80.140, 3508 TC Utrecht, The Netherlands e-mail: m.d.vandoorn@uu.nl

J. J. Hox

Department of Methodology \& Statistics, Utrecht University, P.O. Box 80.140, 3508 TC Utrecht, The Netherlands

\section{Introduction}

Adolescents' dyadic relationships are largely based on the interactions that occur over time between adolescents and their relationship partners. Although not all interactions may have an impact on the relationship, some salient interactions such as conflict may temporarily or permanently affect their relationships, and may improve or worsen them (Kelly et al. 1983). Although the dynamic nature of relationships is widely recognized, most studies assess relationship quality as a relatively static concept and only examine changes over an extended period of time, thereby ignoring daily fluctuations in relationship quality. The current study examines how adolescents navigate through the ups and downs of daily interactions with their parents and best friends by focussing on the consequences of daily conflict for perceived relationship satisfaction. By means of a diary study, we will investigate whether daily conflict and daily perceived relationship satisfaction are related to each other and, more specifically, how different ways of handling conflict are related to perceived relationship satisfaction.

Daily conflict might be different in adolescents' relationships with parents and best friends. According to the social relational model (Laursen and Collins 1994; Laursen et al. 1996), two dimensions that distinguish relationships are closeness and openness. Relationships with parents and friends are both characterized by the highest level of closeness and interdependence, but they differ in openness (Laursen 1996). Openness may be regarded as the ease with which a relationship can be dissolved. Parent-adolescent relationships are closed or involuntary relationships as they are constrained by kinship, norms, and law and they are not easily dissolved. In these relationships, power is often unequally divided. In contrast, relationships with 
friends are open relationships: They are voluntary and they are formed and dissolved more regularly (Laursen and Collins 1994). These relationships are also more egalitarian. The difference in the voluntary nature of these relationships might affect conflict interactions within these relationships.

The way adolescents handle conflict with their parents and friends differs in a way consistent with the social relational model (Laursen and Collins 1994; Laursen et al. 1996). According to this model, conflict behavior varies as a function of the relationship in which conflict arises. With friends, adolescents are aware of the fact that conflict poses threats to the maintenance of their relationships (Hartup 1992). Therefore, adolescents will try to avoid conflict and when conflicts do occur, they tend to avoid expressions of anger and tend to compromise more in order to maintain the friendship (Collins and Steinberg 2006). In contrast, during conflict with their parents, adolescents will be less precautious for these relationships are more likely to endure (Collins et al. 1997). Indeed, adolescents report that they have more conflicts with their parents than with their friends (Adams and Laursen 2001; Furman and Buhrmester 1992; Jensen-Campbell and Graziano 2000). Also, whereas conflict with friends has been found to decline during adolescence (Collins and Laursen 1992), conflict with parents temporarily increases during early adolescence (for a review, see Collins and Steinberg 2006; De Goede et al. 2008; McGue et al. 2005), even though most parent-adolescent relationships remain close (Holmbeck 1996; Smetana et al. 2006). In line with the social relational model, a meta-analysis on conflict management with close peers (defined as friends and romantic partners) and parents (Laursen 1993a) showed that adolescents used more negotiation with close peers than either disengagement (characterized by withdrawal or stand-off) and power assertion (defined as demanding behavior until the other person submits). During conflict with parents, power assertion appeared as the dominant resolution, and negotiation was least often used. Relative to close peers, adolescents reported less negotiation with parents (Laursen 1993a). A meta-analysis on peer conflict resolution showed similar results (Laursen et al. 2001). In contrast, a diary study on the differences between conflict with parents and friends found no significant differences in the use of negotiation during conflict with parents and friends and also showed that adolescents used more verbal insults with friends than with parents (Jensen-Campbell and Graziano 2000). In sum, adolescents' conflict behavior varies as a function of the relationship in which it occurs.

The impact of daily conflict on adolescent relationships with their parents and best friends might also differ in a way consistent with the social relational model. Adolescents seem to discriminate in the way they report about the impact of conflict on relationships. Whereas conflict with close friends has been found to improve more often than worsen relationships, the opposite was true for conflict with parents. More specifically, for most daily conflicts with parents and close friends, adolescents reported that they expect these conflicts to have no long-term effect on their relationship. However, for a substantial part of their daily conflicts with close friends ( $23 \%$ of the conflicts), adolescents reported that they expect these conflicts to even improve their relationship, whereas with parents this was to a much lesser extent the case (about $10 \%$ of the conflicts). There were no differences between adolescents' relationships with parents and close friends in the proportion of conflict that made the relationship worse, which was the case for approximately 15\% of the conflicts (Laursen 1993b).

The associations of daily conflict with relationship satisfaction might depend on the conditions under which conflict takes place (Holmbeck 1996). Research on the consequences or correlates of parent-adolescent conflict showed that conflicts might have different consequences, depending on the conflict behaviors applied during those conflicts. In addition, adolescents' feelings of closeness tend to fluctuate more and seem to be more dependent on the situation (Larson and Richards 1994). For example, the use of a conflict resolution style characterized by aggressive, demanding, or impulsive behavior has been found to be related to lower relational satisfaction (Caughlin and Malis 2004). In contrast, open communication between adolescents and their parents has been found to be related to higher levels of satisfaction with the family (Jackson et al. 1998). Certain conflict behaviors with friends have also been found to be related to negative outcomes. Negative engagement (physical and verbal aggressive behavior) during conflict with friends has been found to be related to lower relationship satisfaction in adolescent boys (Dishion et al. 1995). However, the same study did not find positive engagement (positive nonverbal behavior such as touching, holding and physical interactions and positive verbal behavior such as selfdisclosure) during conflict with friends to be related to higher relationship satisfaction. Thus, in general, whereas negative conflict behaviors have been found to be related to lower levels of relationship satisfaction, positive conflict behaviors have been found to be related to higher levels of relationship satisfaction.

\section{Aims of the Present Study}

In this study we will address five research questions. First, we will investigate the associations between conflict and perceived relationship satisfaction at the individual level: How are conflict and perceived relationship satisfaction 
related to one another? We hypothesize that adolescents who generally have more conflicts with their parents and best friends during the week will also generally be less satisfied with these relationships. Subsequently, we will examine whether conflict and perceived relationship satisfaction are related to one another within individual adolescents at a daily-level: How is conflict on one day related to perceived relationship satisfaction on the same day in a particular relationship? We hypothesize that perceived relationship satisfaction is lower on days on which conflict occurred than on days on which no conflict occurred, for the relationship with both parents and best friends. After examining how conflict on one day is related to perceived relationship satisfaction on the same day, we will investigate how conflict on one day is related to perceived relationship satisfaction one day later. In other words, is there a lagged effect of conflict on perceived relationship satisfaction? As adolescents prospectively indicate that most conflicts with parents have no impact on their relationship (Laursen 1993a, b), we will explore whether the negative relationship between conflict with parents and perceived relationship satisfaction will disappear one day later. Although adolescents prospectively indicate that they expect a certain amount of conflict with friends to improve their relationship (Laursen 1993a, b), it remains unknown whether this relationship can be more objectively established during a one-week period. Instead of asking adolescents to indicate their expectations regarding the long-term influence of conflict, we will investigate the relationship between the occurrence of conflict on one day and perceived relationship satisfaction one day later. We will explore whether conflict with friends will be related to higher perceived relationship satisfaction one day later.

Finally, we will examine how constructively handled conflict and unconstructively handled conflict with parents and best friends are related to perceived relationship satisfaction within individual adolescents at a daily level. In the current study positively handled conflict was measured by the extent to which negotiation and compromising was used by adolescents. Negatively handled conflict involved adolescents' use of either an aggressive conflict resolution style (labeled conflict engagement) or a conflict resolution style characterized by withdrawal. Based on previous research, we expect perceived relationship satisfaction to be lower on days on which either constructively or unconstructively handled conflict occurred than on days on which no conflict took place. Moreover, we hypothesize perceived relationship satisfaction to be lower on days on which unconstructively handled conflict took place than on days on which constructively handled conflict took place. We will also investigate how different ways of handling conflict are related to perceived relationship satisfaction one day later. In other words, is there a lagged effect of conflict type? Although adolescents reported most conflicts to have no effect on perceived relationship satisfaction, they reported some conflicts to improve the relationship and other conflicts to worsen the relationship. We will explore whether a negative lagged effect of conflict with parents and friends will appear for unconstructively handled conflict, and whether a positive lagged effect will appear for constructively handled conflict. All the analyses were carried out for the adolescent-mother, adolescentfather, and adolescent-best friend relationship separately. The focus of the current study will be only on the first nominated best friend, since previous research has shown that this dyadic relationship is much stronger than other types of friendship (i.e., other close friends, such as the second or third nominated friends) (Degirmencioglu et al. 1998; Newcomb and Bagwell 1995). Also, the stability of first nominated best friendships is much higher compared to other friendships (Berndt and Keefe 1995).

\section{Method}

\section{Participants}

The current study uses data from 72 adolescents (40 girls; $55.6 \%$ ), whose age ranged from 14 to 16 years old $(M=15.59, S D=0.46)$. Adolescents named Dutch as their main identity and lived with both parents. Different levels of education were represented in the current study, with $53.5 \%$ of the adolescents at schools preparing for university, $34 \%$ of the adolescents at schools preparing for higher professional education and $12.5 \%$ of the adolescents at schools preparing for lower-level jobs. The adolescents that participated in the diary study were a subsample of the CONAMORE 5-wave longitudinal study (CONflict And Management Of RElationships; author reference). The diary study was conducted approximately 6 months after the fourth annual wave of the main study. In the main study of CONAMORE, 923 early adolescents $(M=12.4, \quad S D=0.6)$ and 390 middle adolescents $(M=16.7$ years, $S D=0.8)$ from twelve high schools located in the province of Utrecht, The Netherlands, annually filled out a battery of questionnaires at school. Sample attrition was $1.6 \%$ up to the fourth wave: the number of participants in Wave 1, 2, 3, and 4 was 1313, 1313,1293 , and 1292, respectively. We selected participants for the current study from the 648 early adolescents who participated in Wave 4, has the Dutch nationality and lived with both parents. Of these 648 early adolescents, 323 adolescents already had participated in another additional study and therefore they were not considered for participation. 
The sample of which the participants were drawn from consequently consisted of 325 adolescents. Since the number of conflicts was found to be low in our sample, which is in line with the fact that it was drawn from a nonclinical population, we decided to use a selection approach in order to increase variance in conflict frequency in the diary study. More specifically, we made sure that about half of the adolescents invited to participate in our study had a score above the 75th percentile of conflict frequency on at least one of three relationships (mother, father, best friend) assessed in Wave 4 of the main study and thus was drawn from the "high conflict" sample $(n=139)$. The other half of the adolescents was randomly selected from the adolescents who scored below the 75 th percentile on this measure at Wave 4 and thus was drawn from the "control" sample $(n=186)$. The 75 th percentile of conflict frequency with mothers, fathers, and best friends was computed for adolescent boys and girls separately.

Our goal was to gather diary data from about 80 adolescents. Taking nonresponse into account, we invited 113 adolescents to participate. Of the initially 113 invited adolescents, 90 agreed to participate in our study, and 72 adolescents actually returned the diary. Of the "conflict participants", 35 out of 58 invited adolescents (60\%) actually returned the diary. Of the "control participants", 37 out of 55 invited adolescents $(67 \%)$ actually returned the diary. A MANOVA showed no differences in adolescents' relationship satisfaction with their mothers, fathers, and best friends as assessed in Wave 4 of the main study and on the conflict resolution styles with mothers, fathers, and best friends as assessed in Wave 4 of the main study between adolescents who returned the diaries $(n=72)$ and adolescents who chose not to participate or to return the diaries $(n=41): F(3$, $106)=1.31, n s$, and $F(9,100)=1.35, n s$, respectively. A MANOVA did show differences in conflict frequency with mothers, fathers, and best friends as assessed in Wave 4 of the main study between adolescents who returned the diaries $(n=72)$ and adolescents who chose not to participate or to return the diaries $(n=41): F(3$, $106)=3.91, p<.05$. Pairwise comparisons showed that adolescents who chose not to participate or to return the diaries had significantly higher levels of conflict in Wave 4 with their best friend than adolescents who returned their diaries. A MANOVA showed no differences between adolescents who chose to participate $(n=90)$ and adolescents who chose not to participate $(n=23)$ on relationship satisfaction, conflict frequency, and conflict resolution styles with their mothers, fathers, and best friends as assessed in Wave 4 of the main study: $F(3$, $106)=0.35, n s, F(3,106)=2.65, n s$, and $F(9,100)=$ $1.46, n s$, respectively.
Procedure

For the main study, both adolescents and their parents received a letter in which the aims of the CONAMORE study were described and, if the adolescent wished to participate, both adolescents and their parents were required to provide written informed consent. Less than $1 \%$ of the adolescents decided not to participate. For the diary study, adolescents received a letter with an invitation to participate in a "diary study concerning the daily lives of adolescents". Adolescents who agreed to participate received the diary by mail. The diary consisted of several questions that had to be filled out daily for seven consecutive days. The adolescents were instructed to fill out the diary each day before they went to bed. When they had forgotten to fill out the diary, they were instructed to fill it out first thing in the morning. The adolescents also received an envelope in which they could return the completed diary. Confidentiality of responses was guaranteed. Adolescents received $€ 10$ (approximately \$12) for their participation. By means of a lottery, ten percent of the participants received an extra $€ 10$.

\section{Measures}

In the current study, we used an adaptation of the Rochester Interaction Record (RIR; Reis and Wheeler 1991; see also Jensen-Campbell and Graziano 2000). The RIR consists of a standardized fixed, Likert-type format. However, its content is intended to be flexible and responsive to the researchers' theoretical interests. This approach has been found to be more accurate and better specified than global self-report questionnaires (Reis and Wheeler 1991). We specifically used the interval-contingent recoding methodology, implying that adolescents had to report their experiences at a certain, predetermined interval.

In the current study, adolescents had to answer questions regarding the relationship with their mothers, fathers, and best friends each day for seven consecutive days. Friendships were assessed by letting each participant nominate their best friend. When adolescents had more than one best friend, they were instructed to choose one. They also had to indicate how many conflicts they had had that day with their mothers, fathers, and best friends. Finally, for each specific conflict that had occurred, they had to fill out to what extent they used each of three conflict resolution styles. On average, adolescents completed 6.9 of the seven days.

\section{Daily Relationship Characteristics}

First, adolescents were asked to indicate the amount of time that they had spent with their mother, father, and best friend 
that day. On days adolescents did not see or spoke to their mother, father, or best friend, they were instructed to skip further questions for that day. Then, they had to rate how satisfied they were with each relationship that day by rating the statement: "I was satisfied today with the relationship with my mother/father/best friend". They had to rate these questions on a 5-point Likert scale ranging from not true at all to entirely true. After that, they had to indicate how many conflicts had occurred that day with their mother, father, and best friend. Conflict was defined as interpersonal disagreement, and participants were instructed as follows (see also Laursen 1995; Shantz 1987): “A disagreement can range from a difference of opinion to an argument. A disagreement does not necessarily mean that someone is angry. For this questionnaire, a disagreement consists of the following: You objected to something someone else said or did, or someone objected to what you said or did; or you and someone else had a quarrel or an argument".

For validation purposes, we computed a mean score for adolescents' perceived relationship satisfaction with their mother when the adolescent had seen his or her mother at least five out of seven days $(n=68)$. We applied the same strategy for computing a mean score for adolescents' perceived relationship satisfaction with their father $(n=61)$. Since adolescents do not necessarily see their best friends on a daily basis (for example they might not go to the same school), we used a less stringent criterion for computing a mean score for adolescents' perceived relationship satisfaction with their best friend: The mean score on perceived relationship satisfaction was computed when the adolescent had seen his or her best friend at least 3 days that week $(n=62)$. We applied the same strategy for the mean level of conflict on a specific day $(n=67, n=62$, and $n=62$ for conflicts with mothers, fathers, and best friends, respectively).

Then, we compared our measures of perceived relationship satisfaction and conflict with global questionnaires on relationship satisfaction (the Satisfaction scale of the Investment Model Scale, see Rusbult et al. 1998) and conflict frequency (the Interpersonal Conflict Questionnaire, see Laursen 1993b, 1995) that were administered 6 months before the diary study was conducted. Pearson's correlations showed that the relationship between the mean level of perceived relationship satisfaction during the diary study and the score on the Satisfaction scale 6 months earlier was $.60, .65$, and .36 , for adolescents' relationships with their mothers, fathers, and best friends, respectively (all $p$ s $<.01$ ). With regard to the conflict measure, Pearson's correlations showed that the relationship between the mean level of conflict during the diary study and the score on the conflict measure six months earlier was $.42, .48$, and .43 , for adolescents' relationships with their mothers, fathers, and best friends, respectively (all $p s<.01$ ).
Further validating our measure, separate composites were computed for perceived relationship satisfaction and conflict on even and odd days. Correlations for perceived relationship satisfaction between even and odd days were $.73, .75$, and .39 for the relationship with mothers, fathers, and best friends, respectively (all $p$ s $<.01$ ). Correlations for conflict between even and odd days were $.60, .54$, and .48 for the relationship with mothers, fathers, and best friends, respectively (all $p \mathrm{~s}<.01$ ). Standard measures of internal consistencies are not appropriate indicators of reliability with diary data, because there is no reason to expect or desire consistency across interactions. However, as some degree of consistency should appear, computing split-half correlations is recommended in this case (Reis and Wheeler 1991).

\section{Conflict Resolution Styles}

For each conflict that had occurred that day, adolescents were asked to fill out what conflict resolution styles they used during the conflict, using the styles Kurdek (1994) distinguished as conflict engagement, positive problem solving, and withdrawal. This questionnaire, originally designed for couples, was modified so that it referred to parents and adolescents. This measure has shown validity in studies on parent-adolescent relationships and friendships (Branje et al. 2008; De Wied et al. 2007; Van Doorn et al. 2008). Each style was measured by one item that was a composite of the original items. Conflict engagement was assessed by the item: "I got angry, assaulted the other person and/or lost self-control". Positive problem solving was measured by the item: "I tried to find a solution that was mutually acceptable and/or tried to discuss our differences of opinion thoroughly". Withdrawal was measured by the item: "I refused to talk about it any longer, did not listen anymore and/or acted as if I did not care about it anymore". Adolescents had to rate to what extend they used each conflict resolution style on a 5-point Likert scale ranging from not true at all to entirely true.

Since we want to compare the occurrence of no conflict on a specific day with the occurrence of conflict that is handled constructively and conflict that is handled unconstructively, we distinguished between no conflict, unconstructively handled conflict, and constructively handled conflict. When adolescents had more than one conflict in a specific relationship on a specific day, the one the adolescent perceived as most important was selected. When conflicts were rated as equally important, we choose one conflict per relationship at random. To construct scores for constructive and unconstructive conflict, we considered the balance between the use of the positive style and the use of the two negative styles: A conflict was classified as "unconstructively handled" when the level of either 
Table 1 The level of conflict engagement, positive problem solving, and withdrawal for dummy variables constructive and unconstructive conflict

\begin{tabular}{|c|c|c|c|c|c|c|}
\hline & \multicolumn{2}{|c|}{ Conflict engagement } & \multicolumn{2}{|c|}{ Positive problem solving } & \multicolumn{2}{|l|}{ Withdrawal } \\
\hline & $M(S D)$ & Range & $M(S D)$ & Range & $M(S D)$ & Range \\
\hline \multicolumn{7}{|l|}{ Constructive conflict } \\
\hline Mothers $(n=68)$ & $1.75(.83)$ & $1-4$ & $3.79(.58)$ & $2-5$ & $1.68(.74)$ & $1-3$ \\
\hline Fathers $(n=48)$ & $1.50(.65)$ & $1-3$ & $3.60(.89)$ & $2-5$ & $1.57(.66)$ & $1-3$ \\
\hline Best friends $(n=42)$ & $1.48(.59)$ & $1-3$ & $3.81(.80)$ & $2-5$ & $1.45(.59)$ & $1-3$ \\
\hline \multicolumn{7}{|l|}{ Unconstructive conflict } \\
\hline Mothers $(n=91)$ & $2.24(1.12)$ & $1-5$ & $2.07(.83)$ & $1-4$ & $2.80(1.14)$ & $1-5$ \\
\hline Fathers $(n=54)$ & $2.56(1.13)$ & $1-5$ & $2.06(.83)$ & $1-4$ & $2.70(1.25)$ & $1-5$ \\
\hline Best friends $(n=24)$ & $2.58(1.21)$ & $1-5$ & $2.17(.92)$ & $1-4$ & $2.67(1.09)$ & $1-5$ \\
\hline
\end{tabular}

Note: $N$ refers to the number of conflicts in that specific category and is based on all days of the week

conflict engagement or withdrawal was higher than or equal to the level of positive problem solving. A constructively handled conflict was identified when the level of positive problem solving was higher than both the level of conflict engagement and the level of withdrawal. Subsequently, we created one dummy variable for constructive conflict resolution (versus no conflict and unconstructively handled conflict) and one dummy variable for unconstructive conflict resolution (versus no conflict and constructive conflict resolution). The occurrence of no conflict was coded 0 for both dummy regressors, so "no conflict" served as a baseline category with which the two conflict resolution types were compared. In that way we were able to compare the contribution of each category on the dependent variable. Table 1 shows that differences in means and in range of scores on the three conflict resolution styles were in the expected direction.

\section{Results}

\section{Descriptive Statistics}

The total number of conflicts with mothers during the week ranged from 0 to 11 and the total number of conflicts with fathers during the week ranged from 0 to 9 . On average, adolescents reported .41 conflicts with their mothers per day $(S D=.40)$ and .26 conflicts per day $(S D=.31)$ with their fathers. The total number of conflicts with best friends ranged from 0 to 5 during the week with an average of .23 conflicts per day $(S D=.31)$. A repeated measures ANOVA showed significant differences between adolescents' mean level of conflict with their mothers, fathers, and best friends: $F(2,51)=7.43, p<.01$. Post hoc comparisons showed that adolescents had significantly more conflicts with their mothers than with their best friends $(p<.01)$. There were no significant differences between the average number of conflicts per day with mothers and fathers, and between the average numbers of conflicts per day with fathers and best friends. There were no differences between boys and girls in mean level of conflict: $F(1,52)=0.74, n s$.

Adolescents' mean level of relationship satisfaction with their mothers, fathers, and best friends was 4.04 $(S D=.56), 4.00 \quad(S D=.66), \quad$ and $4.15 \quad(S D=.44)$, respectively. A repeated measures ANOVA showed no significant differences between adolescents' mean level of relationship satisfaction with their mothers, fathers, and best friends: $F(2,52)=2.55, n s$. There were no differences between boys and girls in mean relationship satisfaction: $F(1,53)=2.16, n s$. The interaction between mean levels of perceived relationship satisfaction and sex of the adolescent was also not significant: $F(2,52)=1.00, n s$. Skewness values of mean level of perceived relationship satisfaction were not significant (the absolute values ranged from -0.21 to .30 ), indicating that these variables did not differentiate much from the normal distribution. The means and standard deviations on the conflict resolution styles are shown in Table 2. Whereas the skewness values of the scores on positive problem solving with mothers, fathers, and best friends were not significant (absolute values ranged from .16 to -.31 ), skewness of the scores on conflict engagement and withdrawal were significant for the relationship with mothers, fathers and best friends (the absolute values ranged from .53 to 1.16). This means that the scores on conflict engagement and withdrawal were positively skewed.

The Relationship Between Mean Level of Conflict and Mean Level of Perceived Relationship Satisfaction

The first research question was how conflict and perceived relationship satisfaction are related to one another. To answer this question, we computed Pearson correlations at the individual level. Correlations showed that there was a 
Table 2 Means, standard deviations, and range of the conflict resolution styles in adolescents' relationships with their mothers, fathers, and best friends

\begin{tabular}{|c|c|c|c|c|c|c|}
\hline & \multicolumn{2}{|c|}{ Mothers $(n=159)$} & \multicolumn{2}{|c|}{ Fathers $(n=102)$} & \multicolumn{2}{|c|}{ Best friends $(n=66)$} \\
\hline & $M(S D)$ & Range & $M(S D)$ & Range & $M(S D)$ & Range \\
\hline Conflict engagement & $2.03(1.03)$ & $1-5$ & $2.06(1.07)$ & $1-5$ & $1.88(1.02)$ & $1-5$ \\
\hline Positive problem solving & $2.80(1.13)$ & $1-5$ & $2.78(1.16)$ & $1-5$ & $3.21(1.16)$ & $1-5$ \\
\hline Withdrawal & $2.32(1.13)$ & $1-5$ & $2.17(1.16)$ & $1-5$ & $1.89(0.99)$ & $1-5$ \\
\hline
\end{tabular}

Note: $N$ refers to the number of conflicts in that particular relationship and is based on all days of the week

significant negative relationship between the average number of conflicts during the week with mothers, fathers, and best friends, and mean levels of perceived relationship satisfaction with mothers, fathers, and best friends $(r=$ $-.47, p<.001, r=-.42, p<.001$, and $r=-.32, p<.05$, respectively). This means that adolescents who had a higher average number of conflicts during the week with their mothers rated the relationship satisfaction with mothers significantly lower than adolescents who had a lower average number of conflicts during the week with their mothers. The same pattern of results was found for adolescent-father and adolescent-best friend relationships.

\section{Diary Data Analysis}

To answer the other research questions, we conducted multilevel analyses. Multilevel modeling, also known as hierarchical linear modeling (HLM), has become the standard data analytic approach for diary data (Bolger et al. 2003). The reasons to conduct multilevel analyses on our data were two-fold. First, the diary data are hierarchically nested. Multiple measurements were collected within individuals over time and therefore these measurements were not independent from each other. A second reason is that multilevel modeling enables examining within-person variability. Indeed, we found in our models that the estimated variance was significant at both levels for each relationship, indicating both between-person variability and within-person variability. In other words, the perceived relationship satisfaction significantly differs between adolescents, but also within adolescents across the days. We used multilevel process analyses, a less familiar application of multilevel modeling that has received more attention recently (Papp 2004). Multilevel process analyses is similar to the growth curve approach, but instead of expecting a more general increase or decline in the dependent variable over time, we expect an increase or decline in the dependent variable caused by a predictor other than time. More specifically, we do not expect relationship satisfaction to decline or increase over the several days. Instead, we expect the occurrence of a conflict to have an impact on the perceived relationship satisfaction. As we focus on the occurrence of conflict and have no predictions regarding growth or decline across the seven days, our data are especially well suited for the multilevel process approach. Our data consisted of 2 levels: level 1 was the day level, and level 2 was the individual level. In our multilevel analyses, we only used level 1 variables (i.e., perceived relationship satisfaction on a particular day, the occurrence of conflict on a particular day, and the use of certain conflict resolution styles on a particular day when there was a conflict that day). Initially, we controlled for sex of the adolescent in our analyses, which is a level 2 variable, but as the effect of sex of the adolescent was not significant and the results did not change, we left sex of the adolescent out of the final model.

\section{The Relationship Between Daily Conflict and Daily Perceived Relationship Satisfaction}

To investigate our second research question, that is, whether the perceived relationship satisfaction is lower on days on which conflict occurred than on days no conflict occurred, we controlled for relationship satisfaction on the day before. Relationship satisfaction on the day before was centered in order to make sure that the intercept can be meaningfully interpreted. By allowing the model to estimate random effects for relationship satisfaction on the day before, we allowed different persons to have different relationships between satisfaction on one day and the next. In our analyses, conflict was recoded into a dichotomous variable (i.e., a score of zero indicated no conflict and a score of one indicated one or more conflicts).

The upper panel of Table 3 shows that relationship satisfaction with mothers and fathers on one day was significantly related to relationship satisfaction one day later, although this relationship was only moderately high in the adolescent-mother relationship. Relationship satisfaction with best friends was not significantly related to relationship satisfaction one day later. Allowing the slope of satisfaction on the day before to vary across individuals, and thus allowing different persons to have different relationships between satisfaction on one day and the next, significantly improved the model for the adolescent-mother and 
Table 3 The relationship between conflict and perceived relationship satisfaction

\begin{tabular}{|c|c|c|c|c|c|c|}
\hline \multirow[t]{3}{*}{ Measure } & \multicolumn{6}{|c|}{ Perceived relationship satisfaction } \\
\hline & \multicolumn{2}{|c|}{ Mothers $(n=361)$} & \multicolumn{2}{|c|}{ Fathers $(n=303)$} & \multicolumn{2}{|c|}{ Best friends $(n=199)$} \\
\hline & $B$ & $\beta$ & $B$ & $\beta$ & $B$ & $\beta$ \\
\hline Intercept & 4.19 & & 4.07 & & 4.23 & \\
\hline Relationship satisfaction on previous day $(t-1)$ & $.14 * *$ & .15 & $.53 * *$ & .51 & .07 & .07 \\
\hline Conflict on current day $(t)$ & $-.63 * *$ & -.37 & $-.53 * *$ & -.25 & $-.50 * *$ & -.28 \\
\hline Intercept & 4.19 & & 4.05 & & 4.18 & \\
\hline Relationship satisfaction on previous day $(t-1)$ & $.13^{*}$ & .14 & $.56^{* *}$ & .54 & $.14 *$ & .14 \\
\hline Conflict on current day $(t)$ & $-.63 * *$ & -.37 & $-.53 * *$ & -.25 & $-.49 * *$ & -.28 \\
\hline Conflict on previous day $(t-1)$ & .00 & .00 & .09 & .04 & $.19 *$ & .11 \\
\hline
\end{tabular}

Note: $N$ refers to the multiplication of number of days and number of persons

$* p<.05 ; * * p<.01$

adolescent-best friend relationship $\left(\Delta \chi^{2}(2)=15.93, p<\right.$ .01 , and $\Delta \chi^{2}(2)=6.07, p<.05$, respectively), but only marginally for the adolescent-father relationship $\left(\Delta \chi^{2}\right.$ (2) $=5.70, p=.06)$. However, in order to be able to compare the different models, we decided to include the random regression coefficient for satisfaction on the day before in the adolescent-father model as well. The variance of the slope of satisfaction on the day before was significant for the relationship with mothers, fathers, and best friends ( $\mu=.11, p<$ $.01, \mu=.08, p<.05$, and $\mu=.09, p<.05$, respectively), indicating that there were also significant differences between individuals in the slope of satisfaction from one day to the next. As can be seen from the upper panel of Table 2, adolescents rated the perceived relationship satisfaction with their mothers, fathers, and best friends significantly lower on days on which conflict occurred than on days no conflict occurred, even when we controlled for relationship satisfaction on the day before.

For our third research question regarding the lagged effect of conflict—or the relationship between conflict and perceived relationship satisfaction one day later-we repeated the former analyses, but now also entered conflict on the day before in the model. Thus, in these analyses we investigated how conflict on one day and relationship satisfaction one day later were related to one another, controlling for relationship satisfaction on the day before, and controlling for concurrent conflict. This approach minimizes the occurrence of floor effects. In addition, Seidman et al. (2004) showed with a simulation study that by using this "full" model regression artifacts or misinterpretations of the findings are unlikely to occur (see also Shrout et al. 2008).

The lower panel of Table 3 displays the results for the third research question. It appeared that conflict with mothers and fathers on one day was not significantly related to perceived relationship satisfaction one day later.
However, conflict with best friends was significantly positively related to perceived relationship satisfaction one day later. This means that conflict with best friends on one day was associated with an increase in perceived relationship satisfaction with best friends one day later.

\section{The Relationship Between Daily Constructive and Unconstructive Conflict and Daily Perceived Relationship Satisfaction}

For our fourth research question, concerning the comparison of the occurrence of no conflict on a specific day with the occurrence of conflict that is handled constructively and conflict that is handled unconstructively, we again allowed different persons to have different relationships between satisfaction on one day and the next. Then the two dummy variables, containing constructive (versus no conflict and constructive conflict) and unconstructive conflict (versus no conflict and unconstructive conflict), were entered into the model.

The results are displayed in the upper part of Table 4 . Both dummy variables labeled constructively and unconstructively handled conflict were significantly negatively related to perceived relationship satisfaction for the relationship with mothers, fathers, and best friends. This means that both constructively handled conflict and unconstructively handled conflict significantly differed from the baseline category (i.e., no conflict). In other words, for all relationships, perceived relationship satisfaction was highest on days on which no conflict occurred, second highest on days on which constructively handled conflict occurred, and lowest on days on which unconstructively handled conflict occurred.

To investigate how different ways of handling conflict are related to perceived relationship satisfaction one day later (Research question 5), we repeated the former 
Table 4 The relationship between constructive conflict, unconstructive conflict and perceived relationship satisfaction

\begin{tabular}{|c|c|c|c|c|c|c|}
\hline \multirow[t]{3}{*}{ Measure } & \multicolumn{6}{|c|}{ Perceived relationship satisfaction } \\
\hline & \multicolumn{2}{|c|}{ Mothers $(n=361)$} & \multicolumn{2}{|c|}{ Fathers $(n=303)$} & \multicolumn{2}{|c|}{ Best friends $(n=199)$} \\
\hline & $B$ & $\beta$ & $B$ & $\beta$ & $B$ & $\beta$ \\
\hline Intercept & 4.18 & & 4.07 & & 4.25 & \\
\hline Relationship satisfaction on previous day $(t-1)$ & $.13^{*}$ & .14 & $.53 * *$ & .51 & .07 & .07 \\
\hline Constructively handled conflict on current day $(t)$ & $-.49 * *$ & -.21 & $-.47 * *$ & -.18 & $-.38 * *$ & -.18 \\
\hline Unconstructive handled conflict on current day $(t)$ & $-.72 * *$ & -.37 & $-.59 * *$ & -.23 & $-.83 * *$ & -.31 \\
\hline Intercept & 4.19 & & 4.05 & & 4.20 & \\
\hline Relationship satisfaction on previous day $(t-1)$ & $.12 *$ & .12 & $.57 * *$ & .55 & $.16^{*}$ & .16 \\
\hline Constructively handled conflict on current day $(t)$ & $-.49 * *$ & -.21 & $-.47 * *$ & -.18 & $-.39 * *$ & -.18 \\
\hline Unconstructive handled conflict on current day $(t)$ & $-.72 * *$ & -.37 & $-.60 * *$ & -.24 & $-.79 * *$ & -.29 \\
\hline Constructively handled conflict on previous day $(t-1)$ & .06 & .03 & .00 & .00 & .13 & .06 \\
\hline Unconstructively handled conflict on previous day $(t-1)$ & -.06 & -.03 & .17 & .07 & $.39 *$ & .15 \\
\hline
\end{tabular}

Note: $N$ refers to the multiplication of number of days and number of persons. The constructively handled conflict variable was coded as follows: $0=$ no conflict and unconstructively handled conflict, $1=$ constructively handled conflict. Unconstructively handled conflict was coded as follows: $0=$ no conflict and constructively handled conflict, $1=$ unconstructively handled conflict

$* p<.05 ; * * p<.01$

analyses but now also entered the dummy variables constructive and unconstructive conflict on the day before in the model. Thus, in these analyses we investigated how constructive conflict, unconstructive conflict, and the occurrence of no conflict on one day and relationship satisfaction one day later were related to one another, controlling for relationship satisfaction on the day before, and controlling for constructive conflict, unconstructive conflict, and the occurrence of no conflict on the same day. Again, this approach minimizes the occurrence of floor effects and possible misinterpretations of the findings (Seidman et al. 2004; Shrout et al. 2008). As can be seen from the lower section of Table 4, neither constructively nor unconstructively handled conflict was related to perceived relationship satisfaction one day later in the adolescent-mother and adolescent-father relationship. This means that conflict with mothers and fathers was not related to perceived relationship satisfaction one day later, regardless of whether conflict was handled constructively or unconstructively. Surprisingly, in the adolescent-best friend relationship, the dummy variable labeled unconstructively handled conflict appeared to be positively related to perceived relationship satisfaction one day later. This means that unconstructively handled conflict differed significantly from the baseline category (i.e., no conflict). The dummy variable constructively handled conflict was not significantly related to perceived relationship satisfaction one day later, meaning that constructively handled conflict did not significantly differ from the baseline category (i.e., no conflict). Taken together, this means that when adolescents handled conflict with their friends unconstructively, the perceived relationship satisfaction one day later was higher than when there was no conflict or when conflict was handled constructively.

\section{Discussion}

The main purpose of the present study was to investigate how daily conflict is related to daily fluctuations in perceived relationship satisfaction. Conflict and perceived relationship satisfaction were found to be negatively related to each other on the same day in adolescents' relationships with their mothers, fathers, and best friends. The way conflicts are handled moderated this association, with unconstructively handled conflict being stronger negatively related to perceived relationship satisfaction than constructively handled conflict. In addition, conflict was positively related to perceived relationship satisfaction with best friends one day later, in particular when these conflicts were unconstructively handled. In line with our hypotheses, differences in the way conflict and relationship satisfaction were related to each other in parent-adolescent relationships and friendships were in line with the nature of these relationships.

\section{Same Day Relationships}

The results clearly show that, in line with our hypothesis, perceived relationship satisfaction in a particular relationship was lower on days on which conflict occurred than on days no conflict occurred in that particular relationship. This was true for adolescents' relationship with their mothers, fathers, and best friends. Further confirming our 
expectations, the way conflict was handled was also found to be related to perceived relationship satisfaction. On days unconstructively handled conflict took place, perceived relationship satisfaction was lower than on days either constructively handled conflict or no conflict took place. Moreover, perceived relationship satisfaction in a particular relationship was lower on days on which constructively handled conflict took place than on days on which no conflict took place in that particular relationship. Again, the same results were found for adolescents' relationship with mothers, fathers, and best friends. Although different correlates and consequences of constructive versus unconstructive conflict behavior have already been found in more traditional research (Dishion et al. 1995; Jackson et al. 1998; Jaffee and D'Zurilla 2003; Oldenburg and Kerns 1997; Rubenstein and Feldman 1993; Tucker et al. 2003), our results extend these findings in that we found similar results at the daily level.

\section{Lagged Effects}

Perhaps the most interesting finding of this study was that we found some remarkable differences between adolescents' relationships with their parents and best friends when we examined the lagged effect of conflict on perceived relationship satisfaction. Not inconsistent with previous research (Laursen 1993a, b), which found that adolescents expect most conflicts with their parents to have no impact on their relationship, we found that the effect of conflict with parents on perceived relationship satisfaction disappeared one day later. Thus, it seems that adolescents' conflicts with their parents are just temporary disruptions in their relationships and that the effect of a single conflict is modest.

Also, extending Laursen's research (1993a, b) that found that adolescents expect a significant proportion of conflict with their friends to improve their relationship, conflict with best friends was indeed found to improve perceived relationship satisfaction one day later. The finding that conflict with best friends improved relationship satisfaction one day later reflects the openness of these relationships. This openness might lead to higher vulnerability of these relationships, which is in agreement with the social relational model (Hartup 1992; Laursen and Collins 1994; Laursen et al. 1996). Whereas adolescents' relationships with their parents will be maintained regardless of the occurrence of conflict, the openness of adolescents' friendships makes them more prone to dissolution. Hence, when conflicts arise, adolescents will have to put more effort into these friendships in order to maintain them. They need to repair the relationship. Also, it is reasonable to imagine that conflict with best friends might be more salient to adolescents than conflict with parents. As a consequence, they might be more inclined to do something about it and restore the disturbed balance. However, we have to take into consideration that these results were based on friendships that were maintained, at least during the week of the diary study. Results might be different when friendships are broken.

When comparing the effect of unconstructively handled conflict and constructively handled conflict, we found neither constructively nor unconstructively handled conflict with parents to have an effect on relationship satisfaction one day later. Thus, again, the effect of a single conflict with parents is modest, regardless of whether it was handled constructively or unconstructively. The current study does not replicate the finding that a proportion of conflicts with parents made the relationship better and a proportion of conflicts made the relationship worse (Laursen 1993a, b). However, we did measure the effect of conflict on perceived relationship satisfaction in a different way than Laursen (1993a, b) did. Perhaps other variables play a role in determining whether conflict has an effect on relationship satisfaction one day later, such as topic, outcome, or intensity of conflict.

In the relationship with best friends, we found especially unconstructively handled conflict to have a positive effect on perceived relationship satisfaction one day later. This was a surprising finding, even more because we found that on the same day unconstructively handled conflict had a more negative impact on perceived relationship satisfaction than constructively handled conflict. Moreover, we would expect that constructively handled conflict would be likely to involve more positive emotions and therefore might be related to higher levels of perceived relationship satisfaction one day later. But again, friendships are vulnerable and conflicts with best friends make adolescents explicitly aware of their open and voluntary relationship. After an unconstructively handled conflict, the need for reparation might be even larger and adolescents might have to put even more effort in the relationship in order to maintain the friendship. The increase in relationship satisfaction one day later raises the question of what happened that day. One possibility is that the day after the conflict they make up and - as a consequence-are temporarily even more satisfied with the relationship than they were before.

Even though we found specific conflicts have a minimal impact on the relationship, this does not mean that there might be no cumulative effect of conflict. Our results at the daily level concern specific conflicts. At the individual level, however, we did find that adolescents who had on average more conflicts during the week with their mothers, fathers, and best friends, also rated the perceived relationship satisfaction during the week with their mothers, fathers, and best friends significantly lower. These results underscore the need to distinguish between daily conflict 
characteristics and their effects and more general dynamics and effects of conflict.

A remarkable finding was that perceived relationship satisfaction on one day was only moderately (and sometimes not significantly) related to perceived relationship satisfaction one day later in the adolescent-mother and adolescent-best friend relationship. In the adolescentfather relationship this association was rather high. What could account for this difference? A reason for the low stability might be due to the method applied, because interaction data ought to vary (Reis and Wheeler 1991). Therefore, we might not expect high correlations from one day to the next. Also, as adolescents had to rate the relationship with their parents and best friends on a daily basis, it is possible that they used the former day as a benchmark for their ratings. In this way, more subtle changes emerge at the daily level that would not be obtained when asking a general perception of the relationship. However, this could not account for the difference in the relationship between perceived relationship satisfaction from one day to the next for adolescents' relationships with mothers and best friends as compared to fathers. We might explain this difference by looking at the characteristics of these specific relationships. For instance, it is known that the relationship adolescents have with their mothers and fathers are distinct and that adolescent-mother relationships are more close and interdependent than adolescent-father relationships (for a review, see Collins and Russell 1991; see also Smetana et al. 2006). Mothers are more involved in adolescents' daily lives than fathers, in that they spend more time raising adolescents than fathers, are engaged in more joint activities, and communicate more with them (Montemayor and Brownlee 1987; Waizenhofer et al. 2004). Therefore, as a consequence, their daily relationship quality might also fluctuate more. The relationship with fathers has been found to be more distant (Youniss and Smollar 1985) and might therefore be more stable. The same reasoning might hold when explaining why perceived relationship satisfaction with best friends is so minimally related from one day to the next. Adolescents are spending a lot of time with their friends and friends are very important in adolescents' lives. Moreover, close friendships are a great source of support and fulfil the need for intimacy (Collins and Steinberg 2006; Csikszentmihalyi and Larson 1984; Furman and Buhrmester 1992; Helsen et al. 2000). Because of the saliency of friends in adolescents' lives, these relationships might also be more sensitive to subtle changes. These findings are also in line with the theoretical idea that friendships, which are open relationships, are more vulnerable to contextual influences and consequently might fluctuate more than closed relationships, such as relationships with parents.
Strengths and Limitations

An important strength of the current study was the use of a daily diary approach. One of the most well-known advantages of diary studies is the substantial decrease of biases which are common to retrospective recalls over relatively long periods. By daily asking adolescents to rate their relationship satisfaction and to indicate how many conflicts they have had that day, recall bias is probably smaller than if we would ask adolescents to recall how many conflicts occurred with their mother, father, and best friend over the last 7 days. Also, as the conflict rate was rather high in our sample, we think this increases the credibility of the responses. In addition, adolescents completed on average 6.9 of the seven days, which was pretty high. Anotherperhaps even more important - advantage of diary studies is the possibility to detect the dynamics of relational processes that underlie within-person variability in adolescent conflict experiences. This means that adolescents' behavior can be compared to their own behavior rather than to another's behavior (Almeida et al. 2001). In sum, diary studies can help determine the correlates and consequences of daily conflict experiences (Bolger et al. 2003).

A few caveats of this study should be noted. Some limitations result from the use of adolescent self-reports of their own conflict behavior. A more objective picture would be derived when parents and best friends also filled out the diary. For instance, we already know that conflicts have a different meaning for parents than for adolescents (Smetana et al. 1991) and that a higher level of conflict appears to be related to lower levels of parents' well-being (Deković 1999). Therefore, the relationship between conflict, conflict resolution, and relationship satisfaction might be different for parents than for adolescents. Also, interactions are based on the behavior of at least two people. When we investigated the relationship between conflict resolution and relationship satisfaction, we only took into account adolescents' conflict behavior. It might also be important to consider the way the other person acted during the conflict, as this person's behavior and certain patterns or interactions of the conflict behavior of both individuals might be better or worse than others.

When interpreting the findings, we should also take into account that causality cannot be implied. Especially with regard to the same day relationships, it is also possible that reduced perceived relationship satisfaction leads to conflict instead of the other way around. A related concern is that it is possible that whatever issue is leading to the conflict might also be causing the lower perceived relationship satisfaction. Finally, participants in our sample were all Dutch adolescents who lived with both parents. Future research should extend our findings to other types of 
families, for example less well-functioning families and single-households.

\section{Conclusions}

The current study provides a better understanding of adolescents' daily lives. By means of a diary study which includes multiple measurements within adolescents, we were able to examine within-person processes. Our results correspond to earlier research in that adolescents' relationships with their parents and friends are different and extend previous research in that we found support for the social relational model at the daily level. The finding that conflicts with parents are just temporary disruptions in these relationships is in line with adolescents' involuntary and more hierarchical relationships with their parents. Moreover, the results are in line with adolescents' awareness of the voluntary nature and vulnerability of their friendships and our results suggest that adolescents seem to act accordingly. How specific conflicts might be related to satisfaction in the relationship on the long-term is unknown. Given our results it is not likely that specific conflicts will have a long-term effect on relationship satisfaction. Future research might investigate moderators in this process. For instance, recurring conflicts that involve the same issue over and over again might have a long-term impact on the relationship satisfaction. It is also possible that daily conflict and perceived relationship satisfaction might fluctuate more during transitional periods and that the conflicts adolescents have during these transitional periods might have a long-term impact on their relationships. Another possibility is that the relationship between conflict and relationship satisfaction is moderated by personality or attachment dimensions such as anxiety. For example, research on romantic relationships found that highly anxious individuals reported lower relationship satisfaction than less anxious individuals on days when they perceived greater conflict (Campbell et al. 2005). Future research might also focus on other measures of interest, for instance adolescent problem behavior. Perhaps adolescents who fluctuate more during a week in the occurrence of conflict and their ratings of relationship satisfaction are more prone for developing problem behavior. Future research might for instance examine daily fluctuations in conflict, relationship satisfaction, and delinquent activities and thereby get a better understanding of processes underlying day-to-day variability. Although these unanswered questions remain, we have provided first insights into the daily dynamics of conflict and relationship satisfaction and found that whereas unconstructively handled conflict with best friends might contribute to better interpersonal relations the next day, conflict with parents does not linger on.

Open Access This article is distributed under the terms of the Creative Commons Attribution Noncommercial License which permits any noncommercial use, distribution, and reproduction in any medium, provided the original author(s) and source are credited.

\section{References}

Adams, R., \& Laursen, B. (2001). The organization and dynamics of adolescent conflict with parents and friends. Journal of Marriage and the Family, 63, 97-110. doi:10.1111/j.1741-3737.2001. 00097.x.

Almeida, D. M., Wethington, E., \& McDonald, D. A. (2001). Daily variation in paternal engagement and negative mood: Implications for emotionally supportive and conflictual interactions. Journal of Marriage and the Family, 63, 417-429. doi:10.1111/j. 1741-3737.2001.00417.x.

Berndt, T. J., \& Keefe, K. (1995). Friends' influence on adolescents' adjustment to school. Child Development, 66, 1312-1329. doi: $10.2307 / 1131649$.

Bolger, N., Davis, A., \& Rafaeli, E. (2003). Diary methods: Capturing life as it is lived. Annual Review of Psychology, 54, 579-616. doi:10.1146/annurev.psych.54.101601.145030.

Branje, S. J. T., van Doorn, M., \& Van der Valk, I. (2008). Parentadolescent conflict, conflict resolution, and adolescent adjustment. Journal of Applied Developmental Psychology (in press).

Campbell, L., Simpson, J. A., Boldry, J., \& Kashy, D. A. (2005). Perceptions of conflict and support in romantic relationships: The role of attachment anxiety. Journal of Personality and Social Psychology, 88, 510-531. doi:10.1037/0022-3514.88.3. 510.

Caughlin, J. P., \& Malis, R. S. (2004). Demand/withdraw communication between parents and adolescents as a correlate of relational satisfaction. Communication Reports, 17, 59-71.

Collins, W. A., \& Laursen, B. (1992). Conflicts and relationships during adolescence. In C. U. Shantz \& W. W. Hartup (Eds.), Conflict in child and adolescent development (pp. 216-241). New York: Cambridge University Press.

Collins, W. A., Laursen, B., Mortensen, N., Luebker, C., \& Ferreira, M. (1997). Conflict processes and transitions in parent and peer relationships: Implications for autonomy and regulation. Journal of Adolescent Research, 12, 178-198. doi:10.1177/07435548971 22003.

Collins, W. A., \& Russell, G. (1991). Mother-child and father-child relationships in middle childhood and adolescence: A developmental analysis. Developmental Review, 11, 99-136. doi: 10.1016/0273-2297(91)90004-8.

Collins, W. A., \& Steinberg, L. (2006). Adolescent development in interpersonal context. In W. Damon \& N. Eisenberg (Eds.), Handbook of child psychology: Vol. 4, Socioemotional processes (pp. 1003-1067). New York: Wiley.

Csikszentmihalyi, M., \& Larson, R. (1984). Being adolescent: Conflict and growth in the teenage years. New York: Basic.

Degirmencioglu, S. M., Urberg, K. A., Tolson, J. M., \& Richard, P. (1998). Adolescent friendship networks: Continuity and change over the school year. Merrill-Palmer Quarterly, 44, 313-337.

De Goede, I. H. A., Branje, S. J. T., \& Meeus, W. H. J. (2008). Developmental changes in adolescents' perceptions of relationships with their parents. Journal of Youth and Adolescence (in press). 
Deković, M. (1999). Parent-adolescent conflict: Possible determinants and consequences. International Journal of Behavioral Development, 23, 977-1000. doi:10.1080/016502599383630.

De Wied, M., Branje, S. J. T., \& Meeus, W. H. J. (2007). Empathy and conflict resolution in friendship relations among adolescents. Aggressive Behavior, 33, 48-55. doi:10.1002/ab.20166.

Dishion, T. J., Andrews, D. W., \& Crosby, L. (1995). Antisocial boys and their friends in early adolescence: Relationship characteristics, quality, and interactional process. Child Development, 66, 139-151. doi:10.2307/1131196.

Furman, W., \& Buhrmester, D. (1992). Age and sex differences in perceptions of networks of personal relationships. Child Development, 63, 103-115. doi:10.2307/1130905.

Hartup, W. W. (1992). Conflict and friendship relations. In C. U. Shantz \& W. W. Hartup (Eds.), Conflict in child and adolescent development (pp. 186-215). New York: Cambridge University Press.

Helsen, M., Vollebergh, W., \& Meeus, W. (2000). Social support from parents and friends and emotional problems in adolescence. Journal of Youth and Adolescence, 29, 319-335. doi:10.1023/ A:1005147708827.

Holmbeck, G. N. (1996). A model of family relational transformations during the transition to adolescence: Parent-adolescent conflict and adaptation. In J. A. Graber, J. Brooks-Gunn, \& A. C. Petersen (Eds.), Transitions through adolescence: Interpersonal domains and context (pp. 167-199). Mahwah, NJ: Erlbaum.

Jackson, S., Bijstra, J., Oostra, L., \& Bosma, H. (1998). Adolescents' perceptions of communication with parents relative to specific aspects of relationships with parents and personal development. Journal of Adolescence, 21, 305-322. doi:10.1006/jado.1998. 0155 .

Jaffee, W. B., \& D'Zurilla, T. J. (2003). Adolescent problem solving, parent problem solving, and externalizing behavior in adolescents. Behavior Therapy, 34, 295-311. doi:10.1016/S0005-7894 (03)80002-3

Jensen-Campbell, L. A., \& Graziano, W. G. (2000). Beyond the school yard: Relationships as moderators of daily interpersonal conflict. Personality and Social Psychology Bulletin, 26, 923 935. doi:10.1177/01461672002610003.

Kelly, H. H., Berscheid, E., Christensen, A., Harvey, J. H., Huston, T. L., Levinger, G., et al. (1983). Close relationships. New York: Freeman.

Kurdek, L. A. (1994). Conflict resolution styles in gay, lesbian, heterosexual nonparent, and heterosexual parent couples. Journal of Marriage and the Family, 56, 705-722. doi:10.2307/352880.

Larson, R., \& Richards, M. H. (1994). Divergent realities: The emotional lives of mothers, fathers, and adolescents. New York: Basic Books.

Laursen, B. (1993a). Conflict management among close peers. In B. Laursen (Ed.), Close friendships in adolescence: New directions for child development (pp. 39-54). San Fransisco: Jossey-Bass.

Laursen, B. (1993b). The perceived impact of conflict on adolescent relationships. Merrill-Palmer Quarterly, 39, 535-550.

Laursen, B. (1995). Conflict and social interaction in adolescent relationships. Journal of Research on Adolescence, 5, 55-70. doi:10.1207/s15327795jra0501_3.

Laursen, B. (1996). Closeness and conflict in adolescent peer relationships: Interdependence with friends and romantic partners. In W. M. Bukowski, A. F. Newcomb, \& W. W. Hartup (Eds.), The company they keep: Friendship in childhood and adolescence (186-210). Cambridge, UK: Cambridge University Press.

Laursen, B., \& Collins, W. A. (1994). Interpersonal conflict during adolescence. Psychological Bulletin, 115, 197-209. doi: 10.1037/0033-2909.115.2.197
Laursen, B., Finkelstein, B. D., \& Townsend-Betts, N. (2001). A developmental meta-analysis of peer conflict resolution. Developmental Review, 21, 423-449. doi:10.1006/drev.2000.0531.

Laursen, B., Hartup, W. W., \& Koplas, A. L. (1996). Towards understanding peer conflict. Merrill-Palmer Quarterly, 42, 76-102.

McGue, M., Elkins, I., Walden, B., \& Iacono, W. G. (2005). Perceptions of parent-adolescent relationship: A longitudinal investigation. Developmental Psychology, 41, 971-984. doi: 10.1037/0012-1649.41.6.971.

Montemayor, R., \& Brownlee, J. R. (1987). Fathers, mothers, and adolescents: Gender-based differences in parental roles during adolescence. Journal of Youth and Adolescence, 16, 281-291. doi:10.1007/BF02139095.

Newcomb, A. F., \& Bagwell, C. L. (1995). Children's friendship relations - a meta analytic review. Psychological Bulletin, 117, 306-347. doi:10.1037/0033-2909.117.2.306.

Oldenburg, C. M., \& Kerns, K. A. (1997). Associations between peer relationships and depressive symptoms: Testing moderator effects of gender and age. The Journal of Early Adolescence, 17, 319-337. doi:10.1177/0272431697017003004.

Papp, L. M. (2004). Capturing the interplay among within- and between-person processes using multilevel modeling techniques. Applied \& Preventive Psychology, 11, 115-124. doi:10.1016/j. appsy.2004.09.002.

Reis, H. T., \& Wheeler, L. (1991). Studying social interaction with the Rochester Interaction Record. Advances in Experimental Social Psychology, 24, 269-318.

Rubenstein, J. L., \& Feldman, S. S. (1993). Conflict-resolution behavior in adolescent boys: Antecedents and adaptional correlates. Journal of Research on Adolescence, 3, 41-66. doi: 10.1207/s15327795jra0301_3.

Rusbult, C. E., Martz, J. M., \& Agnew, C. R. (1998). The Investment Model Scale: Measuring commitment level, satisfaction level, quality of alternatives, and investment size. Personal Relationships, 5, 357-391. doi:10.1111/j.1475-6811.1998.tb00177.x.

Seidman, G., Green, A. S., Rafaeli, E., Shrout, P. E., \& Bolger, N. (2004). Can a statistic artifact make conflict appear good for marital satisfaction? Poster session presented at the annual meetings of the Society for Personality and Social Psychology, Austin, Texas.

Shantz, C. U. (1987). Conflicts between children. Child Development, 58, 283-305. doi: $10.2307 / 1130507$.

Shrout, P. E., Seidman, G., Green, A. S., \& Bolger, N. (2008). Short term benefits of conflict in relationships (Manuscript in preparation).

Smetana, J. G., Campione-Barr, N., \& Metzger, A. (2006). Adolescent development in interpersonal and societal contexts. Annual Review of Psychology, 57, 255-284. doi:10.1146/annurev.psych. 57.102904.190124.

Smetana, J. G., Killen, M., \& Turiel, E. (1991). Children's reasoning about interpersonal and moral conflicts. Child Development, 62, 629-644. doi:10.2307/1131136.

Tucker, C. J., McHale, S. M., \& Crouter, A. C. (2003). Conflict resolution: Links with adolescents' family relationships and individual well-being. Journal of Family Issues, 24, 715-736. doi:10.1177/0192513X03251181.

Van Doorn, M. D., Branje, S. J. T., \& Meeus, W. H. J. (2008). Conflict resolution in parent-adolescent relationships and adolescent delinquency. The Journal of Early Adolescence (in press).

Waizenhofer, R. N., Buchanan, C. M., \& Jackson-Newsom, J. (2004). Mothers' and fathers' knowledge of adolescents' daily activities: Its sources and its links with adolescent adjustment. Journal of Family Psychology, 18, 348-360. doi:10.1037/0893-3200.18.2.348.

Youniss, J., \& Smollar, J. (1985). Adolescent relations with mothers, fathers, and friends. Chicago: The University of Chicago Press. 


\section{Author Biographies}

Muriel Van Doorn is a $\mathrm{PhD}$ candidate at Utrecht University. She received her master's degree in 2003 from Maastricht University. Her research interests include conflict in adolescent relationships with parents and friends.

Susan Branje is an Associate Professor at Utrecht University. She received her PhD in 2003 from the Radboud University Nijmegen. Her research interests include adolescent development and the influence of parents and friends.
Joop Hox is Professor of Social Research Methodology at Utrecht University. He received his $\mathrm{PhD}$ in 1986 from the University of Amsterdam, the Netherlands. His research interests include multilevel modeling and data quality in surveys.

Wim Meeus is Professor of Adolescent Development and chair of the Research Centre of Adolescent Development at Utrecht University, the Netherlands. He received his PhD in 1984 from Utrecht University. His research interests include identity formation, relationships, and developmental psychopathology in adolescence. 